\title{
Correction to: Distribution Mechanisms of Ghana's Free Senior High School Policy: The Equity Dimensions and Ameliorating Measures
}

\author{
Timothy Chanimbe ${ }^{1}$ D $\cdot$ Paa Kwesi Wolseley Prah $^{1}$
}

Published online: 18 May 2020

(c) Springer Nature B.V. 2020

\section{Correction to: Interchange https://doi.org/10.1007/s10780-020-09403-3}

The published version of this article contained a mistake. Under the Introduction section, 5th paragraph was inadvertently eliminated. The missing paragraph is given below. The original article has been corrected.

The backdrop of low enrolments and completion rates kindled the President's (presidential candidate as he then was) campaign promise of ensuring an absolutely free senior high school policy if elected in December 2016. This message may have convinced most citizens, to elect him and in fulfilment of the promise, the free senior high school policy was implemented (Offei, 2018: Ayorkor \& Bessa, 2017). After implementing this policy, Prempeh (2018) revealed that 361,371 students enrolled in secondary schools compared to the 308,799 in the previous $2016 / 2017$ academic year. Projections were that 472,730 students shall enrol in the 2018/2019 academic year, depicting a swift rise in enrolment. In the same vein, Addae et al. (2019) and Nurudeen et al. (2018) confirmed that this reform put more students in schools than previous funding schemes. Meanwhile, Secondary schools in Ghana are mainly classified as either day or day/boarding schools, either single-sex or mixed (both males and females), stratified into category A, B and C (where A is somewhat resourced whilst $\mathrm{B}$ and $\mathrm{C}$ are less resourced). Secondary education programmes are either academic or technical/vocational (https://ghstudents.com/wp-content/uploads/2019/06/ GES-SHSselection-REGISTER-2019.pdf). This categorization has bred inequities widening student achievement gaps between students in less resourced schools

The original article can be found online at https://doi.org/10.1007/s10780-020-09403-3.

Timothy Chanimbe

tchanimbe14@gmail.com

Paa Kwesi Wolseley Prah

wolseleyprah@yahoo.com

1 Faculty of Culture and Social Science, University of Osnabrueck, Osnabrück, Germany 
and those in somewhat resourced schools as well as the gaps between the technical and academic tracks of secondary education. This does not only affect achievement gaps but also reputation of less endowed academic as well as technical schools (Amedome \& Fiagbe, 2013). This suggests the secondary education system lacks equal access to quality and equality of learning conditions across all schools. With equity among the aims of the free senior high school policy (http://freeshs.gov.gh/ index.php/free-shs-policy/) and the heavy focus of literature on access and enrolment rates, we investigate the distribution of policy resources in 6 diverse schools to assess whether the distribution of resources bridge the inequities across schools to enable all students enjoy equal access to quality and learning conditions. To carry out this research, a policy document about the distribution mechanism shall be analysed and supplemented by interviews to ascertain the realities on the ground. We engage school leaders from six schools different schools with varying forms of secondary education delivery, resource status and gender which shall be discussed in the methodological section.

Publisher's Note Springer Nature remains neutral with regard to jurisdictional claims in published maps and institutional affiliations. 